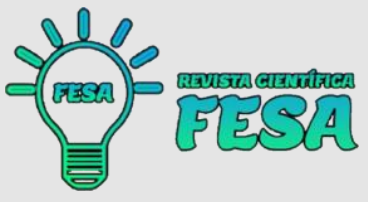

\title{
UMA ANÁLISE DO CASO CHAN KIM CHANG À VISTA DA RES- PONSABILIDADE INTERNACIONAL
}

\author{
Petter Ondeza ${ }^{1}$
}

\section{RESUMO}

A responsabilidade internacional representa uma questão de elevada importância frente as atividades do Direito Internacional, particularmente, as que se encontram relativas ao meio ambiente, a crimes de guerra ou crimes contra a humanidade. Desse modo, o presente trabalho, utilizandose do método dedutivo, versará sobre o conceito de Responsabilidade Internacional, apresentando e explicitando os princípios norteadores de tal direito, tendo por base o caso concreto que será analisado.

Palavras-chaves: Responsabilidade Internacional; Corte Internacional de Justiça; Tribunal Penal Internacional; Caso Chan Kim Chang; Comissão de Direito Internacional.

\section{RESUMEM}

La responsabilidad internacional es una cuestión de gran importancia frente a las actividades del derecho internacional, en particular las relacionadas con el medio ambiente, los crímenes de guerra o los crímenes de lesa humanidad. Así, el presente trabajo, utilizando el método deductivo, abordará el concepto de Responsabilidad Internacional, presentando y explicando los principios rectores de dicho derecho, a partir del caso específico que será analizado.

Palabras clave: Responsabilidad Internacional; Corte Internacional de Justicia; Corte Penal Internacional; caso Chan Kim Chang; Comisión de Derecho Internacional.

\section{ABSTRACT}

International responsibility is a matter of high importance in the face of the activities of international law, particularly those relating to the environment, war crimes or crimes against humanity. Thus, the present work, using the deductive method, will deal with the concept of International Responsibility, presenting and explaining the guiding principles of such right, based on the specific case that will be analyzed.

Keywords: International Responsibility; International Court of Justice; International Criminal Court; Chan Kim Chang case; Commission on International Law.

\footnotetext{
${ }^{1}$ Mestrando em ciências Jurídico-Políticas pela Universidade Portucalense Infante D. Henrique na cidade do Porto em Portugal, pós-graduado em Ciências Penais e Direito Processual Civil pela Universidade Cândido Mendes, graduado em Direito pela Universidade Moacyr Sreder Bastos. Atualmente dedicado a seguir a carreira acadêmica e de escritor. E-mail: petter.ondeza@hotmail.com
}

\section{Multifaces do Conhecimento Científico: Teoria e Prática}




\section{INTRODUÇÃO}

Uma das principais características de um Estado é o seu poder de soberania, porém, esta, pode ser positiva ou negativa. Entende-se por soberania negativa a capacidade de um Estado de impedir a interferência de outrem em sua ordem interna, enquanto a soberania positiva, consiste no talento de influenciar outros Estados a terem papeis relevantes nas decisões internacionais.

A responsabilidade internacional é um ramo do direito que está mais ligada à política do que ao direito propriamente dito. Observe que, em que pese o Direito Internacional seja repleto de normas e regulamentações, este seria inviável se não houvesse uma política de cooperação entre os Estados.

Para que esta política da boa vizinhança não sofra rupturas, é necessário que cada Estado tenha a capacidade de prevenção para que em seu território não ocorram atos que violem as leis de responsabilidade internacional ou, em caso de violação, seja capaz de punir de forma adequada o indivíduo infrator, ainda que este o represente.

No estudo apresentado a seguir, analisaremos o caso Chan Kim Chang, um chinês de aproximadamente quarenta anos que após ser preso no aeroporto Tom Jobim e conduzido para detenção no presídio Ary Franco, localizado no bairro de Água Santa no Rio de Janeiro, veio a óbito após sofrer a prática do crime de tortura.

O objetivo deste estudo é, ao final da análise, podermos afirmar se, no caso apresentado, o crime praticado pelos servidores públicos é passível de responsabilidade internacional. Caso sim, saber, ainda, quem poderia ser responsabilizado internacionalmente por esta prática e quais as consequências que poderiam gerar esta violação.

\section{CONCEITOS E FUNDAMENTOS DA RESPONSABILIDADE INTERNACIO-} NAL

A matéria de responsabilidade internacional lida com uma das formas mais relevantes das relações internacionais e, conforme bem pontuado pelo Presidente da CCCDI, as suas normas são, de algum aspecto, as regras 
fundamentais de todo ordenamento jurídico. Constitui uma parte adiposa da base do direito internacional e tem formado importante jurisprudência arbitral desde o século IX.

O labor da compilação desta área do direito internacional teve partida com a SDN e alcançou uma grande influência com as resoluções da Assembleia Geral das Nações Unidas, criando a presente Comissão de Direito Internacional.

A CDI laborou num propósito de concordância a respeito da responsabilidade internacional de cada Estado pela prática de fatos ilícitos, convertendo as normais de costume que já existiam e pondo em prática um desenvolvimento gradual.

A Comissão de Direito Internacional teve de enfrentar inúmeras críticas, tendo sido colocado a prova uma ínfima chance da sua vitória. A despeito de todas as objeções que sofreu, a CDI efetuou o seu trabalho de forma exemplar e este demonstrou-se de extrema qualidade.

A Responsabilidade Internacional do Estado é a instituição jurídica através da qual o Estado a quem foi imputado um ato ilícito, segundo as normas e as diretrizes do direito internacional, deverá uma indenização para aquele contra quem $o$ ato fora cometido.

Isto é, a responsabilidade internacional do Estado advém de uma violação ao regulamento jurídico internacional, assim como da existência de uma atuação de caráter doloso ou culposo do autor, que de ensejo a uma deliberação a respeito da responsabilidade subjetiva e objetiva do Estado.

No que tange à responsabilidade subjetiva, para além da infração de um ordenamento jurídico internacional por parte do Estado, deverá este ter procedido com dolo ou culpa para que seja consagrado responsável no âmbito internacional.

Quanto à responsabilidade objetiva do Estado, esta é estabelecida pela infração de uma obrigação jurídica internacional independente de existir dolo ou culpa garantidos, logo produz maior segurança jurídica na área das relações internacionais.

Nas palavras de Mello (2004):

[...] a responsabilidade internacional apresenta características próprias em relação à responsabilidade no direito interno: a) ela é sempre uma responsabilidade com a finalidade de reparar o prejuízo; o DI 
praticamente não conhece a responsabilidade penal (castigo, etc.); b) a responsabilidade é de Estado a Estado, mesmo quando é um simples particular a vítima ou o autor do ilícito; é necessário, no plano internacional, que haja o endosso da reclamação do Estado nacional da vítima, ou ainda, o Estado cujo particular cometeu o ilícito é que virá a ser responsabilizado. (MELLO, 2004)

Sem empecilho, quanto às divergências doutrinárias a respeito da matéria, tem se nomeado as condições a seguir, quanto à verificação da responsabilidade do Estado no âmbito internacional: (1) infração de uma norma jurídica de caráter internacional; (2) a transgressão da regra deve originar um dano; e (3) a ofensa deve ser imputável ao Estado.

Estendo o assunto, Soares (2002) destaca que, para que esteja caracterizado a responsabilidade de reparação de dano do direito internacional, faz-se obrigatório o incidente dos seguintes elementos: (a) um comportamento em violação de um dever internacional, sempre imputável a um ou mais Estados, denominado ilícito internacional, consistente numa ação ou omissão; (b) a existência de um dano físico moral, causado a outros Estados, sua integridade territorial ou a bens a estes pertencentes ou, ainda, a pessoas ou propriedades dos nacionais destes; e (c) um nexo de causalidade normativa entre dano e ilícito, o qual institui um dever de reparar ao seu autor e cria ao ofendido um direito subjetivo de exigir uma reparação. (SOARES, 2002)

Uma vez que o Estado assuma a responsabilidade da prática de um ilícito, a ordem internacional deixará de se manifestar quanto ao assunto. Será considerada atraída a competência da violação de uma norma a um Estado, quando essa competência for recepcionada por ele mesmo. Essa declaração terá validade, quer seja realizada de forma direta ou implícita.

A intervenção do direito internacional na imputação dos atos ilícitos aos Estados costuma ser considerada autônoma em relação a considerações do direito interno do Estado em causa. No entanto, esta pretensa autonomia não se pode ter como plena pois tudo o que o Direito Internacional faz neste domínio acaba por ser levar em conta uma situação objetiva e conseguir afirmar a responsabilidade internacional a partir da regulamentação limitativa de imputação que o direito interno costuma fixar.

Muitas vezes, inclusivamente, a imputação de um ato a um Estado nem resulta numa "ampliação" dos limites internos de responsabilidade de certos 
órgãos, mas, é, sim, o resultado no plano internacional do direito à auto-organização. (FERREIRA, 2006)

\section{CASO CHAN KIM CHANG}

Em 25 de agosto do ano de 2003, o comerciante chinês naturalizado brasileiro Chan Kin Chang, a época com 46 anos de idade, ao tentar embarcar num voo com destino aos EUA, foi preso pelos servidores da polícia federal no Aeroporto do Galeão (Antônio Carlos Jobim) por tentar deixar o país com 30.500 dólares não declarados à Receita Federal.

O chinês, foi conduzido ao encarceramento da Polícia Federal, que tomava parte da galeria "A", da unidade prisional Ary Franco e, ali, permaneceu até o dia 27 , data em que foi encontrado inconsciente dentro da cela, com suas vestimentas molhadas e apresentando escoriações por todo o corpo na antessala da diretoria do presídio em questão.

Segundo os relatos, o detido teria sido encontrado aproximadamente as $16 \mathrm{~h}$ do dia 27, e até as $22 \mathrm{~h} 30$ ainda não havia sido prestado o devido socorro.

Consta da declaração preenchida pelo Major Luiz Gustavo Matias, Diretor da Unidade Prisional que, o detento, teria sido apresentado ao estabelecimento penal já apresentando diversas escoriações, sendo levado posteriormente a enfermaria para medicação e tratamento. Segundo os termos do relatório preenchido, ao adentrar o setor de enfermaria o detento teria entrado em surto psicológico e se esgueirado pelo chão até chocar-se de cabeça contra a quina de um arquivo, fato confirmado pelos agentes de plantão.

O chinês foi levado para o Hospital Salgado Filho onde deu entrada em estado de coma, apresentando derivados edemas, quadro de isquemia, lesões na parte direita da cabeça, para além de múltiplas escoriações por todo o corpo.

Decorridos 08 (oito) dias de sua entrada em estado de coma ao hospital, o chinês veio a óbito no dia 04/09/2003 em decorrência do sofrimento de traumatismo craniano e pneumonia dupla.

As controvérsias sobre o caso iniciam-se a partir do momento da detenção de Chan Kim Chang, o diretor do Presidio Ary Franco, assim como os inspetores penitenciários e alguns detentos presentes no local afirmam que o chinês já deu entrada na unidade apresentando as escoriações e os demais edemas descritos, 
entretanto, os agentes da Polícia Federal responsáveis pela prisão negão veementemente o ocorrido.

Após a conclusão do inquérito, em 06 de outubro de 2003, ocorreu o oferecimento da denúncia e o caso foi levado para a 4ำ Vara Federal Criminal do Rio de Janeiro para ser processado e julgado.

O condenado a cumprir pena de 14 anos por assalto e tráfico de drogas, Fabiano de Oliveira Costa, ao depor secretamente na Justiça federal em Brasília, afirmou ter havido crime por parte dos agentes.

Em seu depoimento ele afirma trabalhar na inspetoria do presídio Ary Franco e ter presenciado tanto a chegada do chinês quanto as agressões sofridas.

Ao descrever os fatos, ele relata que Chang deu entrada na unidade prisional nervoso e assustado e se recusava a realizar o procedimento padrão de tirar fotos para o cadastramento interno da unidade prisional.

Segundo o relato do preso, o agente Everson Azevedo Motta, conhecido por agente Motta, juntamente com o agente Sarmento e outros três presos conhecidos como Duda, Cláudio Gordinho e Trique-Trique, indignados por não conseguir realizar o procedimento das fotos e algemar o chinês, iniciaram uma sessão de agressões que após o início fora acompanhada por outros agentes.

O juiz substituto da $4^{\circ}$ Vara Federal Criminal, Dr. Alexandre Berzosa Saliba, ao prolatar a sentença do caso, entendeu pela materialidade do crime de tortura, julgando procedente a pretensão punitiva estatal para condenar os réus (agentes penitenciários) pela prática do crime de tortura tipificado na Lei oㅜ 9.455/97 e seus artigos e parágrafos, sendo a maior pena aplicada a de 16 anos e a menor pena aplicada a de 04 anos, para todos os envolvidos.

\section{DA RESPONSABILIDADE INTERNACIONAL}

Apresentado o caso em fomento, passemos agora para análise das condições para verificação da responsabilidade do Estado no âmbito internacional.

Para tanto, num primeiro momento, devemos verificar se a infração penal cometida fere uma norma jurídica de caráter internacional, a fim de averiguar se, estão presentes, as condições de responsabilidade. 
No Brasil, a tortura encontra-se delimitada na Lei 9.455/97 que prediz o seguinte:

Art. 1․ Constitui crime de tortura: I - Constranger alguém com emprego de violência ou grave ameaça, causando-Ihe sofrimento físico ou mental: a. Com o fim de obter informação, declaração ou comissão da vítima ou de terceira pessoa; b. Para revocar ação ou comissão de natureza criminosa; c. Em razão de discriminação racial ou religiosa II - Submeter alguém, sob sua guarda, poder ou autoridade, com emprego de violência ou grave ameaça, a intenso sofrimento físico ou mental, com forma de aplicar castigo pessoal ou medida de caráter preventivo. (BRASIL, 1997)

Note-se que, por ser o crime de tortura um crime contra a humanidade, nós iremos encontrá-lo também tipificado no Estatuto de Roma do Tribunal Penal Internacional, em seu art. $7^{\circ}, 1$, alínea "f"

Art. 7ํ- - Crimes Contra a Honra a. Homicídio; b. Extermínio; c. Escravidão; d. Deportação ou transferência forçada de uma população; e. Prisão ou outra forma de privação da liberdade física grave, em violação das normas fundamentais de direito internacional; f. Tortura (...) (BRASIL, 2002)

Há também a menção na Convenção Americana sobre Direitos Humanos (pacto de são José da Costa Rica) em seu art. 5ํ, 2., senão, vejamos:

\begin{abstract}
Art. 5ํ - Direito a Integridade Pessoal 1. Toda Pessoa tem o direito de que se respeite sua integridade física, psíquica e moral. 2. Ninguém deve ser submetido a torturas, nem a penas ou tratos cruéis, desumanos ou degradantes. Toda pessoa privada de liberdade deve ser tratada com o respeito devido à dignidade inerente ao ser humano. (COSTA RICA, 1969)
\end{abstract}

Assim, após uma análise direta, porém, minuciosa das normas supracitadas, não restam dúvidas que ao praticar o crime de tortura, aquele que a prática fere uma norma jurídica de caráter internacional, conforme a previsão dos artigos $1^{\circ}$ e $2^{\circ}$ do PARI, senão, vejamos:

Art. $1^{\circ} \mathrm{A}$ responsabilidade do Estado por seus atos internacionalmente ilícitos. Todo ato internacionalmente ilícito de um Estado acarreta sua responsabilidade internacional.

Art. $2^{\circ}$ Elementos de um ato internacionalmente ilícito do Estado.

Há um ato internacionalmente ilícito do Estado quando a conduta, consistindo em uma ação ou omissão:

a. é atribuível ao Estado consoante o Direito Internacional; e 
b. constitui uma violação de uma obrigação internacional do Estado. (MAZZUOLI, 2013)

Observe que no momento em que o Estado pratica o ato e infringi as normas supracitadas, nós estamos diante do que se considera Fato Gerador.

Uma vez consumado o crime de tortura nós teremos a Conduta, prevista no art. $4^{\circ}, 2$, do PARI, conforme a transcrição abaixo:

Art. $4^{\circ}$ - Conduta dos órgãos de um Estado

1. Considerar-se-á ato do Estado, segundo o Direito Internacional, a conduta de qualquer órgão do Estado que exerça a função legislativa, executiva, judicial ou outra qualquer que seja sua posição na organização do Estado e, independentemente de se tratar de órgão do governo Central ou de unidade territorial do Estado.

2. Incluir-se-á como órgão qualquer pessoa ou entidade que tenha tal status de acordo com o direito interno do Estado. (MAZZUOLI, 2013)

Neste ponto, podemos observar que conforme disciplina o item "2" do art. $4^{\circ}$ do PARI, o Estado responde pela conduta praticada por seus agentes durante o exercício da função ou em razão desta.

Todavia, outro fator deve ser levado em consideração, isto é, devemos considerar se o país praticante da infração é signatário dos tratados internacionais, para que possa ser responsabilizado internacionalmente, conforme prediz $o$ art. 13 do PARI:

Art. 13 - Obrigação internacional em vigor para um Estado. Um ato de um Estado não constitui uma violação de uma obrigação, a menos que o Estado esteja vinculado pela obrigação em questão no momento em que o ato ocorre. (MAZZUOLI, 2013)

O Brasil, em 06 de novembro de 1992, ratificou a Convenção Americana sobre os Direitos Humanos e, posteriormente, em 25 de setembro de 2002, ratificou o Estatuto de Roma do Tribunal Penal Internacional, aderindo-os em todos os seus termos.

O crime do caso em comento fora praticado em 23 de agosto de 2003, portanto, após a adesão do Brasil aos Tratados Internacionais. Desta forma, resta caracterizada a Ilicitude tipificada no art. 12 do PARI, conforme a transcrição a seguir:

Art. 12 - Existência de uma violação de uma obrigação internacional. Há uma violação de uma obrigação internacional por um Estado 
quando um ato deste estado não está em conformidade com o que lhe é requerido pela obrigação, seja qual for a origem ou natureza dela. (MAZZUOLI, 2013)

O Governo brasileiro, a fim de que não pairassem dúvidas quanto a que espaço ocupam os tratados ratificados por este na legislação brasileira, votou e publicou a Emenda Constitucional № 45 que disciplina que os Tratados e convenções internacionais sobre direitos humanos que forem aprovados, em cada casa do Congresso Nacional, em dois turnos, por três quintos dos votos dos respectivos membros, serão equivalentes às emendas constitucionais.

Portanto, apreende-se do contexto que, no que tange a primeira condição para a responsabilização do Estado e de seus agentes quanto a responsabilidade internacional, isto é, a infração de uma norma jurídica de caráter internacional, podemos afirmar que o caso em estudo se coaduna com a conduta tipificada.

Outrossim, não restam dúvidas quanto a imputação da autoria dos fatos à Secretaria de Administração Penitenciária nos moldes do art. 4ํ do PARI, a medida em que a conduta fora praticada por seus agentes durante o exercício da função.

Assim, passamos agora à análise prática da segunda condição que ensina que a transgressão da regra deve ser capaz de gerar um dano ao Estado, sua integridade territorial ou a bens a estes pertencentes ou ainda, a pessoas ou propriedades dos nacionais destes.

Neste prisma, devemos delimitar o que é dano material e dano moral a fim de observarmos se no caso em tela houve transgressão a esses bens juridicamente tutelados.

O direito a vida, está garantido no art. $4^{\circ}, 1$. do Pacto de São José da Costa Rica que, prediz o seguinte:

Art. 4․ Direito a Vida

1. Toda Pessoa tem o direito de que se respeite sua vida. Esse direito deve ser protegido pela lei e, em geral, desde o momento da concepção. Ninguém pode ser privado da vida arbitrariamente. (COSTA RICA, 1969) 


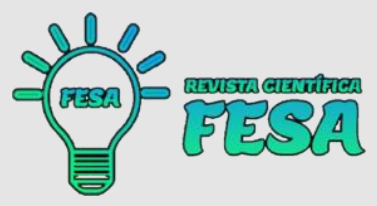

Adiante, conforme já podemos observar anteriormente, em seu art. 5ํㅇ o Pacto de São José da Costa Rica irá tratar do direito a integridade física de cada indivíduo.

Entretanto, convém ressaltar que, o direito à vida e à integridade física não estão garantidos apenas nos tratados internacionais pois, por se tratar de direito de primeira grandeza, estes também vêm resguardados nas constituições de cada país.

A Constituição Portuguesa em seu art. 24ํㅗ 1. E 2., prediz que a vida humana é inviolável e em caso algum poderá haver pena de morte. Em seu art. 25ํㅜ 1. E 2. do mesmo título, prediz que a integridade moral e física das pessoas é inviolável e ninguém pode ser submetido a tortura, nem a tratos ou penas cruéis, degradantes ou desumanas.

Já a Constituição Brasileira, trará as garantias a vida e a integridade física do cidadão em seu art. 5ำ III, que prevê a igualdade de todos perante a lei, não podendo haver distinção de quaisquer naturezas, garantindo-se a todos os direitos a vida, a liberdade a igualdade e a segurança, sendo vedada a submissão de tortura ou tratamento desumano ou degradante.

No que tange à responsabilidade internacional, nós encontraremos a tipificação para a responsabilidade da reparação do dano no art. 31, 1 e 2 do PARI, conforme transcrição abaixo;

\footnotetext{
Art. 31 - Reparação

1. O Estado responsável tem obrigação de reparar integralmente o prejuízo causado pelo ato internacionalmente ilícito.

2. O prejuízo compreende qualquer dano, material ou moral, causado pelo ato internacionalmente ilícito de um Estado. (MAZZUOLI, 2013)
}

Assim, não há dúvidas quanto a insurgência de dano físico, isto é, material, no caso apresentado. Note-se que, a violência dispensada a integridade física da vítima é o resultado naturalístico da violação do bem jurídico tutelado.

Para além disso, no caso em epígrafe, a violência atingiu o resultado morte, violando não apenas o direito a integridade física do detido, mas, também, o direito à vida que, por questões constitucionais deveriam ser resguardados pelo Estado.

Além da questão do dano físico, podemos observar no caso em tela a existência do dano moral, decorrente do efeito da lesão, e não da lesão em si.

\section{Multifaces do Conhecimento Científico: Teoria e Prática}




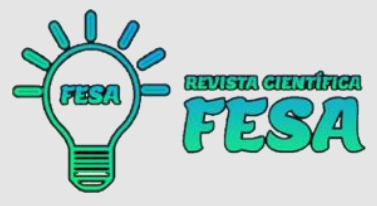

O dano moral se consagra na dor, no sofrimento, na angústia sentida pela parte que teve o seu bem juridicamente tutelado violado de forma ilegal ou arbitrária.

Para a reparação dos danos o PARI previu em seus artigos 35, 36 e 37, respectivamente a restituição, indenização e a satisfação, senão vejamos:

\footnotetext{
Art. 35 - Restituição

Um Estado responsável por um ato internacionalmente ilícito tem a obrigação de restituir, ou seja, de restabelecer a situação que existia antes que $o$ ato ilícito fosse cometido, desde que na medida que a restituição;

a. Não seja materialmente impossível;

b. Não acarrete um ônus totalmente desproporcional com relação ao benefício que derivaria de restituição em vez da indenização.

Art. 36 - Indenização

1. O estado responsável por um ato internacionalmente ilícito tem obrigação de indenizar pelo dano causado por este, desde que tal dano não seja reparado pela restituição.

2. A indenização deverá cobrir qualquer dano susceptível de mensuração financeira, incluindo lucros cessantes, na medida de sua aprovação.

Art. 37 - Satisfação

1. O Estado responsável por um ato internacionalmente ilícito tem a obrigação de dar satisfação pelo prejuízo causado por aquele ato desde que ele não possa ser reparado pela restituição ou indenização. (MAZZUOLI, 2013)
}

O caso Chang é um exemplo claro da conjugação entre o dano físico sofrido pela vítima no interior das unidades prisionais e o dano moral sofrido pela família, advindo da dor pela perda de um ente querido. Note-se que, é impossível se mensurar toda a angústia e sofrimento sentido pelos familiares e parentes, restando incontestável a presença do dano e seu enquadramento nos artigos supracitados.

Devemos destacar que, no caso do presente artigo, uma vez que o dano resultou na morte do paciente, estamos diante de restituição material impossível, conforme previsto no art. 35, "a" do PARI.

Porém, tendo em vista a previsão legal do art. 36 do PARI, que versa sobre a indenização como forma de reparação e compensação, o Estado foi condenado ao pagamento vitalício de pensão mensal a viúva do Chines na importância de 03 (três) salários-mínimos.

No caso em tela, ao final da instrução processual não restaram dúvidas quanto a prática de tortura exercida pelos agentes do Estado quer de forma comissiva, quer de forma omissiva. Desta forma, por ser a responsabilidade do

\section{Multifaces do Conhecimento Científico: Teoria e Prática}

Periódico Multidisciplinar da Facility Express Soluções Acadêmicas - ISSN: 2676-0428 
Estado objetiva encontraram-se preenchidas todas as condições necessárias para a responsabilidade do Estado no âmbito das Relações Internacionais.

Contudo, devemos nos atentar para a seguinte peculiaridade do caso in comento. No problema trazido à baila, poderão ser responsabilizados tanto o Estado, quanto o servidor que praticou o ato de tortura. Em caso de ser o Estado a ser responsabilizado internacionalmente, será competente para julgá-lo e processá-lo a Corte Internacional de Justiça.

A CIJ compõe um dos principais órgãos da ONU, que tem sua base no Palácio da Paz, nos países baixos em Haia. A Corte Internacional de Justiça teve como predecessora a CPJI, isto é, a Corte Permanente de Justiça Internacional instituído o primeiro tribunal internacional com ampla jurisdição, instaurado no período do surgimento da Liga das Nações.

Por outro lado, se for o servidor a ser julgado, isto é, o indivíduo, a competência para processá-lo será do Tribunal Penal Internacional (TPI), criado com o intuito de julgar pessoas individualmente pela prática dos crimes internacionais tipificados no Estatuto de Roma.

O Tribunal Penal Internacional constitui uma formação independente e não pertence a organização da ONU, em que pese mantenha uma ligação intima com esta organização.

O sentido que tem prevalecido com relação a atos hostis praticados por indivíduos ou grupos de pessoas sugere que o Estado que exerça a soberania de um determinado território responda por ter infringido o seu dever internacional de prevenção ou de repressão penal desses atos, esse dever também é chamado de princípio da diligência devida.

Os pilares das normas de imputação presentes no Projeto da CDI, compondo uma expressão efetiva do Direito Internacional em voga, não podem ser entendidos como uma verdade pré-jurídica coberta de lógica absoluta. Antes, constituem princípios jurídicos de Direito Internacional que se baseiam na prática diplomática, na jurisprudência internacional etc., tendo em vista que, outro desenlace, no mínimo em teoria, seria impossível.

Assim sendo, toda vez que um Estado avocar para si a responsabilidade de um ilícito internacional ocorrido em seu território, não haverá motivo para que a Ordem Internacional interfira ou se posicione de forma diferente. 


\section{CONSIDERAÇÕES FINAIS}

O caso analisado à luz do Pacto de São José da Costa Rica e do Estatuto de Roma, configura claramente crime de Responsabilidade Internacional. O crime se origina da falha do Estado em prevenir ou reprimir determinado tipo de conduta, culminando na possibilidade de ser responsabilizado tanto o Estado perante a Corte Internacional de Justiça quanto o indivíduo perante o Tribunal Penal Internacional.

Todavia, na demanda apresentada o Estado avocou para si a responsabilidade pela apuração e julgamento dos fatos ocorridos terminando por punir os responsáveis pela prática do delito em questão.

Em que pese o Estado tenha processado e punido de forma exemplar os responsáveis direto pela prática criminosa, a União, também não escapou ao dever de reparar os danos provocados conforme pode se apreender do processo de $n^{\circ}$ 2005.02.01.007021-1, onde, esta, foi condenada ao pagamento de pensão mensal no valor de 03 salários-mínimos à viúva da vítima.

Desta forma, tanto o Estado enquanto ente Federativo, quanto seus servidores foram responsabilizados internamente pela infração a uma norma de responsabilidade internacional. Observe que, a penalização interna, sofrida dentro de seu país de origem, afasta a possibilidade de que aquele Estado ou seu indivíduo seja processado e julgado perante a Corte ou Tribunal Internacional.

Ante todo o exposto concluímos que, a Corte Internacional de Justiça assim como o Tribunal Penal Internacional não têm o condão somente de processar e julgar os crimes de responsabilidade internacional praticados por Estados ou indivíduos, antes, para além disso, servem como Órgão que exerce pressão política para que os Estados aderentes, sintam-se de certa forma pressionados a fazer cumprir as normas estabelecidas nos tratados e convenções ratificados.

\section{REFERÊNCIAS BIBLIOGRÁFICAS}

ÂMBITO JURÍDICO. Responsabilidade Internacional do Estado. Disponível em: http://www.ambito-juridico.com.br/site/index.php?n link=revista artigos leitura\&artigo id=7670 Acesso em: 22 de junho de 2019. 


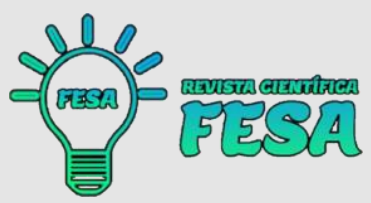

BRASIL. Define os crimes de tortura e dá outras providências. Lei no 9.455 de 07 de abril de 1997. Disponível em: http://www.planalto.gov.br/ccivil 03/leis/L9455.htm Acesso em: 22 de junho de 2019.

BRASIL. Decreto no 678. Promulga a Convenção Americana sobre Direitos Humanos (Pacto de São José da Costa Rica), de 22 de novembro de 1969 em 06 de novembro de 1992. Disponível em: http://www.planalto.gov.br/ccivil 03/decreto/d0678.htm Acesso em: 22 de junho de 2019.

BRASIL. Emenda Constitucional no $\mathbf{4 5}$ de 30 de dezembro de 2004. Disponível em: http://www.planalto.gov.br/ccivil 03/constituicao/emendas/emc/emc45.htm Acesso em: 22 de junho de 2019.

BRASIL. Decreto no 4.388, Promulga o Estatuto de Roma do Tribunal Penal Internacional em 25 de setembro de 2002. Disponível em: http://www.planalto.gov.br/ccivil 03/decreto/2002/D4388.htm Acesso em: 22 de junho de 2019.

BRASIL. Lei no 9.455, de 07 de abril de 1997. Disponível em: http://www.planalto.gov.br/ccivil 03/leis/L9455.htm Acesso em: 22 de junho de 2019.

BRASIL. Decreto no 4.388 de 25 de setembro de 2002. Disponível em: http://www.planalto.gov.br/ccivil 03/decreto/2002/D4388.htm Acesso em: 22 de junho de 2019.

CIDH. Comissão Interamericana de Direitos Humanos. Disponível em: https://cidh.oas.org/que.port.htm Acesso em: 22 de junho de 2019.

CONJUR. União terá de pagar pensão à viúva de chinês morto na cadeia. Disponível em: https://www.conjur.com.br/2006-jan-04/uniao indenizar viuva chines morto cadeia Acesso em: 22 de junho de 2019.

COSTA RICA. Convenção Americana de Direitos Humanos - Pacto de São José da Costa Rica. Disponível em: http://www.pge.sp.gov.br/centrodeestudos/bibliotecavirtual/instrumentos/sanjose.htm Acesso em: 22 de junho de 2019.

FERREIRA, Nuno. A responsabilidade internacional: evolução na tradição. Ordem dos Advogados. Ano 66, Vol. II, Set, 2006.

GONÇALVES, Carlos Roberto. Comentário ao Código Civil. Volume XI, Editora Saraiva: São Paulo, 2003, pag.07

MAZZUOLI, Valerio de Oliveira. Curso de direito internacional público. 7. ed. Rev. dos Tribunais, 2013. p. 588.

MELLO, Celso Albuquerque de. Direito internacional Público. Rio de Janeiro: Renovar, 2004, v. I, p. 138

RODRIGUES, Silvio. Direito Civil. Volume IV, Editora Saraiva, 19ª Edição, São Paulo, 2002, pag. 10. 
SOARES, Guido Fernando Silva. Curso de direito internacional público. São Paulo: Atlas, 2002, p. 186.

TERATOLOGIA CRIMINAL. Caso Chan Kim Chang. Disponível em: http://teratologiacriminal.blogspot.com/2013/08/caso-chan-kim-chang-rio-de-janeirori.html Acesso em: 22 de junho de 2019.

TJSP. O Dano na Responsabilidade Civil. Disponível em: http://www.tjsp.jus.br/download/EPM/Publicacoes/ObrasJuridicas/rc7.pdf?d=636680468024086265 Acesso em: 22 de junho de 2019.

TRF-2. Tribunal Regional Federal da $2^{a}$ Região. Apelação Criminal. Disponível em: https://trf-2.jusbrasil.com.br/jurisprudencia/8292747/apelacao-criminal-acr200351015157701-ri-20035101515770-1/inteiro-teor-13518691 Acesso em: 22 de junho de 2019. 